This document is the Accepted Manuscript version of a Published Work that appeared in final form in Applied Materials \& Interfaces, (C) 2016 American Chemical Society after peer review and technical editing by publisher. To access the final edited and published work see Liang, H., Liu, B., Yuan, Q., \& Liu, J. (2016). Magnetic Iron Oxide Nanoparticle Seeded Growth of Nucleotide Coordinated Polymers. Acs Applied Materials \& Interfaces, 8(24), 15615-15622. https://doi.org/10.1021/acsami.6b04038

\title{
Magnetic Iron Oxide Nanoparticle Seeded Growth of Nucleotide Coordinated Polymers
}

\author{
Hao Liang, ${ }^{* a, b}$ Biwu Liu, ${ }^{\mathrm{b}}$ QipengYuan, ${ }^{\mathrm{a}}$ and Juewen Liu*b \\ ${ }^{a}$ State Key Laboratory of Chemical Resource Engineering, Beijing University of Chemical \\ Technology, Beijing, China. E-mail: lianghao@mail.buct.edu.cn \\ ${ }^{\mathrm{b}}$ Department of Chemistry and Waterloo Institute for Nanotechnology, University of
}

Waterloo, Waterloo, Canada. E-mail: liujw@uwaterloo.ca; Fax: +1 519 7460435; Tel: +1 519 8884567 ext. 38919 


\section{Abstract}

Introducing functional molecules to the surface of magnetic iron oxide nanoparticles (NPs) is of critical importance. Most previously reported methods were focused on surface ligand attachment either by physisorption or covalent conjugation, resulting in limited ligand loading capacity. In this work, we report the seeded growth of a nucleotide coordinated polymer shell, which can be considered as a special form of adsorption by forming a complete shell. Among all the tested metal ions, $\mathrm{Fe}^{3+}$ is the most efficient for this seeded growth. A diverse range of guest molecules including small organic dyes, proteins, DNA, and gold NPs can be encapsulated in the shell. All these molecules were loaded at a much higher capacity compared to that on the naked iron oxide NP core, confirming the advantage of the coordination polymer $(\mathrm{CP})$ shell. In addition, the $\mathrm{CP}$ shell provides better guest protein stability compared to simple physisorption, while retaining guest activity as confirmed by the entrapped glucose oxidase assay. The use of this system as a peroxidase nanozyme and as a glucose biosensor was demonstrated, detecting glucose down to $1.4 \mu \mathrm{M}$ with excellent stability. Together, this work describes a new way of functionalizing inorganic materials with a biocompatible shell.

Keywords: Magnetic nanoparticle; iron oxide; encapsulation; AMP; nucleotides, self-assembly, coordinated polymers 


\section{Introduction}

Hybrid nanomaterials with a magnetic core are highly important for biosensor development, catalysis, drug delivery, and separation. ${ }^{1-5}$ Among the various magnetic materials, iron oxide (e.g $\mathrm{Fe}_{3} \mathrm{O}_{4}$ ) is particularly attractive due to its biocompatibility, cost-effectiveness, and strong magnetism. ${ }^{6-11}$ A few methods are available to form hybrid materials with iron oxide. First, since direct chemical conjugation on iron oxide in water is difficult, the particles are often coated with a layer of hydrophobic ligand followed by ligand exchange, making it a technically demanding process. ${ }^{10,12-14}$ Second, biomolecules can be physisorbed on the particle surface, but the stability of the complex is low. ${ }^{15}$ Third, magnetic particles can be wrapped by other materials such as silica, ${ }^{16}$ carbon,,${ }^{17}$ gold,,${ }^{18}$ and dextran, ${ }^{19}$ or grown on substrates such as graphene oxide. ${ }^{20}$ Then biomolecules can be linked to the shell or substrate. However, none of the above methods are general for incorporating different types of molecules/materials at a high capacity to the particle surface, and these methods require multiple steps of operation.

Coordination polymers (CPs) are functional organic-inorganic hybrid materials formed by metal ions and bridging organic ligands. ${ }^{21-22} \mathrm{CPs}$ have versatile applications due to their mild polymerization conditions, porosity, and high guest entrapment efficiency. Many biomolecules have multiple metal binding sites and CPs constructed with these ligands have good biocompatibility. ${ }^{23}$ Various biomolecules, such as nucleotides, ${ }^{24-25}$ amino acids, ${ }^{26-27}$ peptides, ${ }^{28-29}$ and protein ${ }^{30-32}$ have been used to construct CPs. Nucleotides have excellent metal coordination properties for both soft metals (e.g. binding to the nucleobases) and hard metals (e.g. binding to the phosphate and nucleobases). ${ }^{33}$ Nucleotide coordinated materials 
were already used in preparing metal-organic frameworks, ${ }^{34} \mathrm{NPs},{ }^{24,}, 35-37$ and hydrogels. ${ }^{38-39}$ We and others demonstrated that CPs are capable of adsorbing and entrapping a broad range of molecules. ${ }^{24,35,39}$

Given the encapsulation ability of CPs, an interesting question is whether CPs can grow on iron oxide NP seeds and incorporate guest molecules at the same time. If so, a convenient, efficient, and high capacity method might be derived for introducing various materials and molecules upon the magnetic core. Herein, we aim to test this hypothesis using nucleotides for metal coordination.

\section{Materials and Methods}

Chemicals. Adenine, adenosine, adenosine 5'-monophosphate disodium salt (AMP), adenosine 5'-triphosphate disodium salt hydrate (ATP), guanosine 5'-monophosphate disodium salt hydrate (GMP), cytidine 5'-monophosphate disodium salt (CMP), thymidine 5'-monophosphate disodium salt (TMP), fluorescein, rhodamine B, rhodamine 6G, albumin-fluorescein isothiocyanate conjugate (F-BSA), ferric chloride, copper dichloride, zinc chloride, aluminum chloride, calcium chloride, magnesium chloride, nickel dichloride, cobalt dichloride, sodium chloride, glucose oxidase (GOx) from Aspergillus, 2, 2'-azinobis (3-ethylbenzothiazoline-6-sulfonic acid) diammonium salt (ABTS), 3,3',5,5'tetramethyl-benzidine (TMB), $\mathrm{Fe}_{3} \mathrm{O}_{4} \mathrm{NPs}$, glucose, fructose, galatose, and sucrose were from Sigma-Aldrich. 4-(2-hydroxyethyl)-1-piperazineethanesulfonic acid (HEPES) was from Mandel Scientific (Guelph, ON). Milli-Q water was used to prepare all the buffers and solution. 
Preparation of CPs. In a typical experiment, the nucleotide/ $\mathrm{Fe}^{3+}$ complexes were prepared by mixing $100 \mu \mathrm{L} \mathrm{FeCl}_{3}(50 \mathrm{mM}), 200 \mu \mathrm{L}$ nulceotides $(25 \mathrm{mM})$ and $700 \mu \mathrm{L}$ HEPES buffer (50 mM, pH 7.6). The samples were centrifuged at 6,000 rpm for $5 \mathrm{~min}$ and washed with Milli-Q water to remove remaining chemicals. Different concentrations and $\mathrm{pH}$ of HEPES buffer were used to study the coordination of $\mathrm{Fe}^{3+}$ and AMP.

DLS and TEM. The coordination complexes $(2 \mathrm{mg} / \mathrm{mL})$ were re-dispersed into a HEPES buffer (10 mM, pH 7.6) by vortex mixing for DLS measurement (Zetasizer Nano 90, Malvern) at $25{ }^{\circ} \mathrm{C}$. $\zeta$-potential was measured using the dip-cell set-up. TEM was formed on a Philips CM10 transmission electron microscope at $100 \mathrm{kV}$. The sample was prepared by pipetting a drop of the aqueous dispersion of the coordination complexes onto a 230 mesh holy carbon copper grid and the sample was dried on a filter paper.

Seeded growth on $\mathrm{Fe}_{3} \mathrm{O}_{4}$ NPs. The $\mathrm{Fe}_{3} \mathrm{O}_{4}$ NPs and Fe/AMP complexes were prepared by mixing $200 \mu \mathrm{L}$ AMP (25 mM), $200 \mu \mathrm{L} \mathrm{Fe}_{3} \mathrm{O}_{4}$ NPs $(1 \mathrm{mg} / \mathrm{mL}), 500 \mu \mathrm{L}$ HEPES buffer $(25$ $\mathrm{mM}, \mathrm{pH} 8.0)$, and $100 \mu \mathrm{L} \mathrm{FeCl}_{3}(50 \mathrm{mM})$. The samples were attracted by the external magnet and washed with Milli-Q water to remove remaining chemicals. The obtained precipitants were used for TEM experiment. Other metal salts, such as $\mathrm{CuCl}_{2}, \mathrm{ZnCl}_{2}, \mathrm{AlCl}_{3}, \mathrm{CaCl}_{2}$, $\mathrm{MgCl}_{2}, \mathrm{NiCl}_{2}$, and $\mathrm{CoCl}_{2}$, were also individually tested by the same method.

Encapsulation of guest molecules. In a typical experiment, $200 \mu \mathrm{L}$ AMP $(25 \mathrm{mM}), 200 \mu \mathrm{L}$ $\mathrm{Fe}_{3} \mathrm{O}_{4}$ NPs $(1 \mathrm{mg} / \mathrm{mL})$, and $2 \mu \mathrm{L}$ dye $(5 \mathrm{mM})$ (or $10 \mu \mathrm{L}$ F-BSA, $5 \mathrm{mg} / \mathrm{mL} ; 2 \mu \mathrm{L}$ DNA, 100 $\mu \mathrm{M}$; or $100 \mu \mathrm{L}$ of $13 \mathrm{~nm}$ AuNPs, $10 \mathrm{nM}$ ) were mixed in $500 \mu \mathrm{L}$ HEPES buffer $(25 \mathrm{mM}$, pH 8.0). Then $100 \mu \mathrm{L} \mathrm{FeCl}_{3}(50 \mathrm{mM})$ was added. The products were separated using a magnet and the guest in the supernatant was quantified using fluorescence or UV-vis spectrometry. 
Peroxidase assays. Freshly prepared $\mathrm{Fe}_{3} \mathrm{O}_{4} @ \mathrm{Fe} / \mathrm{AMP}$ NPs were re-dispersed into $1 \mathrm{~mL}$ Milli-Q water to a final concentration of $2.2 \mathrm{mg} / \mathrm{mL}$. For the ABTS assay, $5 \mu \mathrm{L}$ of the $\mathrm{Fe}_{3} \mathrm{O}_{4} @ \mathrm{Fe} / \mathrm{AMP}$ suspension, $20 \mu \mathrm{L} \mathrm{H}_{2} \mathrm{O}_{2}(100 \mathrm{mM})$, and $5 \mu \mathrm{L}$ ABTS $(10 \mathrm{mM})$ were added into $165 \mu \mathrm{L}$ acetate buffer (pH 4). For the TMB assay, $10 \mu \mathrm{L}$ TMB (10 mM) was added. The absorbance for ABTS or TMB was immediately recorded at $415 \mathrm{~nm}$ or $652 \mathrm{~nm}$, respectively. The same amounts of Fe/AMP CPs and $\mathrm{Fe}_{3} \mathrm{O}_{4}$ NPs were studied under the same condition.

Immobilization of GOx. Different concentrations of GOx solutions were prepared by diluting a GOx stock (5 mg/mL) using HEPES buffer (25 mM, pH 8.0). Then, immobilization of GOx was performed by a quick mixing $500 \mu \mathrm{L}$ of GOx solution (containing 50, 100, 150, 200, or $250 \mu \mathrm{g}$ GOx), $200 \mu \mathrm{L}$ AMP $(25 \mathrm{mM}), 200 \mu \mathrm{L} \mathrm{Fe} \mathrm{O}_{4} \mathrm{NPs}(1 \mathrm{mg} / \mathrm{mL})$ and $100 \mu \mathrm{L}$ $\mathrm{FeCl}_{3}(50 \mathrm{mM})$. After $1 \mathrm{~h}$, the immobilized enzymes were collected by a magnet. The obtained GOx\&Fe $\mathrm{O}_{4} @ \mathrm{Fe} / \mathrm{AMP}$ complexes were re-dispersed in $1 \mathrm{~mL}$ Milli-Q water for further experiments.

Enzyme cascade reaction and glucose detection. In a typical assay, $20 \mu \mathrm{L}$ of glucose (100 $\mathrm{mM})$ solution and $10 \mu \mathrm{L}$ ABTS $(10 \mathrm{mM})$ were added into $160 \mu \mathrm{L}$ acetate buffer (pH 4), and then mixed with $10 \mu \mathrm{L}$ GOx\&Fe $\mathrm{O}_{4} @ \mathrm{Fe} / \mathrm{AMP}$ complex (containing $0.9 \mu \mathrm{g} \mathrm{GOx}$ ). The absorbance was immediately recorded at $415 \mathrm{~nm}$. For glucose detection, different concentrations of glucose were added into $180 \mu \mathrm{L}$ acetate buffer $(\mathrm{pH} 4)$ containing $10 \mu \mathrm{L}$ the suspension of the GOx\&Fe $\mathrm{O}_{4} @ \mathrm{Fe} / \mathrm{AMP}$ complexes and $10 \mu \mathrm{L}$ ABTS $(10 \mathrm{mM})$. After $1 \mathrm{~h}$ incubation at room temperature, the solution was centrifuged at 10,000 rpm for $5 \mathrm{~min}$. The absorbance of the supernatant at $415 \mathrm{~nm}$ was measured. In all the experiments, the error bars were calculated based on the standard deviation from three independent measurements. 


\section{Results and Discussion}

CPs formed by $\mathrm{Fe}^{3+}$ and nucleotides. Various nucleobases, nucleosides, and nucleotides can coordinate with metal ions. ${ }^{40}$ For example, trivalent lanthanide ions react with nucleotides to form NPs. ${ }^{24}$ Adenosine and $\mathrm{Au}^{3+}$ form luminescent NPs after citrate reduction and UV light exposure, ${ }^{41,42}$ while non-fluorescent materials were obtained by mixing adenine and $\mathrm{Au}^{3+} \cdot{ }^{36}$ We recently found that $\mathrm{Zn}^{2+}$ coordinates with adenosine monophosphate (AMP) to form hydrogels. ${ }^{39}$ In this work, since we are interested in coating iron oxide NPs, the most appropriate metal is iron. Since $\mathrm{Fe}^{2+}$ is easy oxidized in air, we tested $\mathrm{Fe}^{3+}$ first.

When $\mathrm{FeCl}_{3}$ and AMP were mixed in $10 \mathrm{mM}$ HEPES buffer (pH 7.4), no visible precipitation was observed, which is consistent with our previous report. ${ }^{39}$ Interestingly, precipitation occurred by increasing the HEPES concentration (Figure 1A). With $35 \mathrm{mM}$ HEPES, yellow precipitants formed in a few minutes after adding $\mathrm{FeCl}_{3}$. To quantify the yield, all the samples were centrifuged and weighed (Figure 1B, red triangles). The AMP remained in the supernatant was also measured using UV-vis spectroscopy to confirm that the precipitant contained AMP instead of simple iron hydroxide (Figure 1B, black squares). Below $25 \mathrm{mM}$ HEPES, the yield was very low. Further increase of HEPES concentration increased the yield. Nearly all the added AMP was reacted with $\mathrm{Fe}^{3+}$ giving the highest yield with $35 \mathrm{mM}$ HEPES buffer. We also tested MOPS buffer and similar precipitants were formed. Thus, the role of HEPES is likely to be a simple buffer. Other common buffers such as phosphate and citrate cannot be used since they strongly chelate metal ions.

$\mathrm{Fe}^{3+}$ is easily hydrolyzed and this hydrolysis reaction can lower the solution $\mathrm{pH}$. With a 
final of $5 \mathrm{mM} \mathrm{FeCl}_{3}$, a low concentration of HEPES might not achieve the intended $\mathrm{pH}$. We measured the $\mathrm{pH}$ of these solutions and marked them in Figure 1A. Indeed, it took $35 \mathrm{mM}$ HEPES to approach the intended $\mathrm{pH}$ 7.4. Next, we further studied the reaction between $\mathrm{Fe}^{3+}$ with AMP at different pH's (Figure S1, Supporting Information), and a similar trend was observed. This experiment indicates the coordination of $\mathrm{Fe}^{3+}$ by AMP is inhibited at low $\mathrm{pH}$, suggesting that the $\mathrm{N} 1$ position of adenine $\left(p K_{\mathrm{a}}=3.5\right)$ is involved in $\mathrm{Fe}^{3+}$ coordination since it is the only position that can be protonated. By fixing the $\mathrm{pH}$ at 6.3 , we varied the ionic strength, and the yield was higher with higher $\mathrm{NaCl}$ concentrations (Figure S2).

To further understand CP formation, we also tested the phosphate and ribose parts of the nucleotide by reacting $\mathrm{Fe}^{3+}$ with adenine and its derivatives in $35 \mathrm{mM}$ HEPES buffer ( $\mathrm{pH}$ 7.4). After centrifugation, no precipitant formed with ATP, while only a small amount of brown precipitant formed with adenine or adenosine (Figure 1C). Therefore, it is important to have just one phosphate linked to the nucleotide. ATP probably carries too many negative charges to prevent $\mathrm{CP}$ aggregation. ${ }^{41}$

Next, we tested other nucleotides (GMP, CMP, and TMP), and all formed precipitants with $\mathrm{Fe}^{3+}$ (Figure 1D), while the yield was the lowest with TMP. Dynamic light scattering indicated most of these CPs were in the range of 350 650 nm (Figure S3). Since these samples are poly-dispersed, the DLS data may not reflect the true size distribution. Thus we further performed TEM analysis. The chemical structures of all the tested nucleoside monophosphates are shown in Figure S4 and the TEM micrographs of their $\mathrm{Fe}^{3+} \mathrm{CPs}$ are in Figure S5, where chain-like aggregated structures are observed. In the pH 7.6 HEPES buffer, the $\zeta$-potential of all these CPs are around $-30 \mathrm{mV}$ (Table S1), which may explain that $\mathrm{NaCl}$ 
can increase the CP yield by charge screening. The contents of iron and phosphorus in the formed $\mathrm{Fe}^{3+} / \mathrm{AMP}$ CPs were analyzed by ICP, which indicates a 1:1 ratio of these two in the final complex based on the iron and phosphorus contents (Table S3). Overall, AMP appears to be an optimal ligand for $\mathrm{Fe}^{3+}$ coordination, and their reaction scheme is shown in Figure 1E.
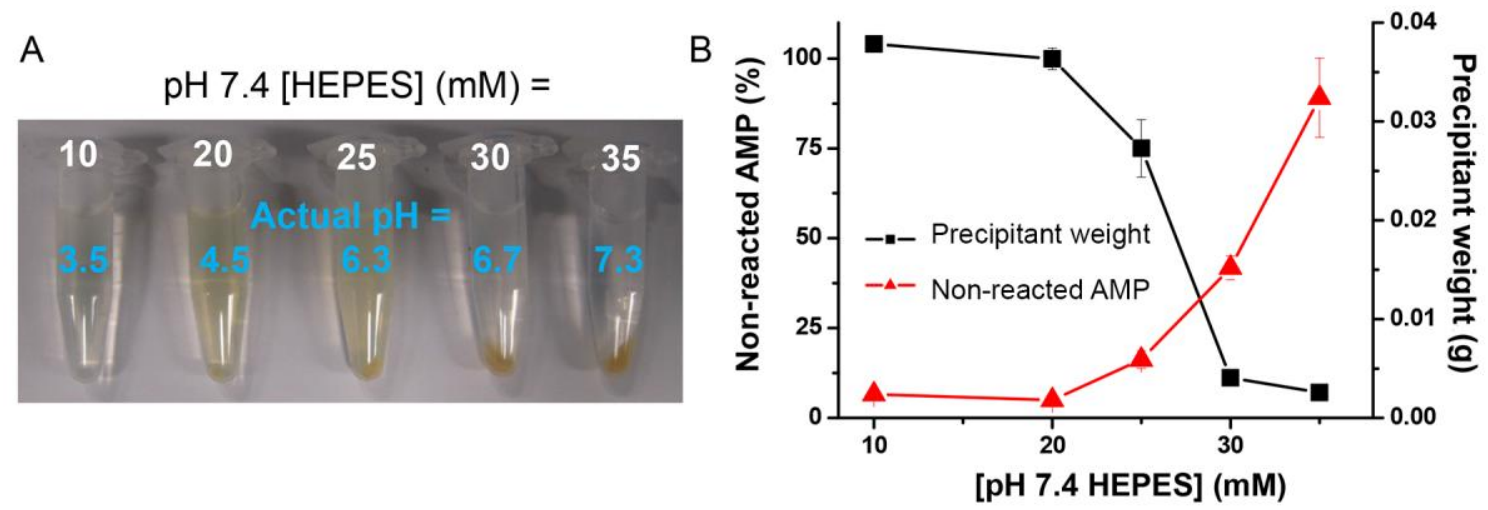

C

35 mM HEPES, pH 7.6

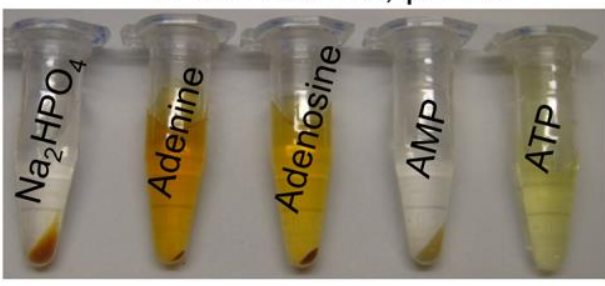

D
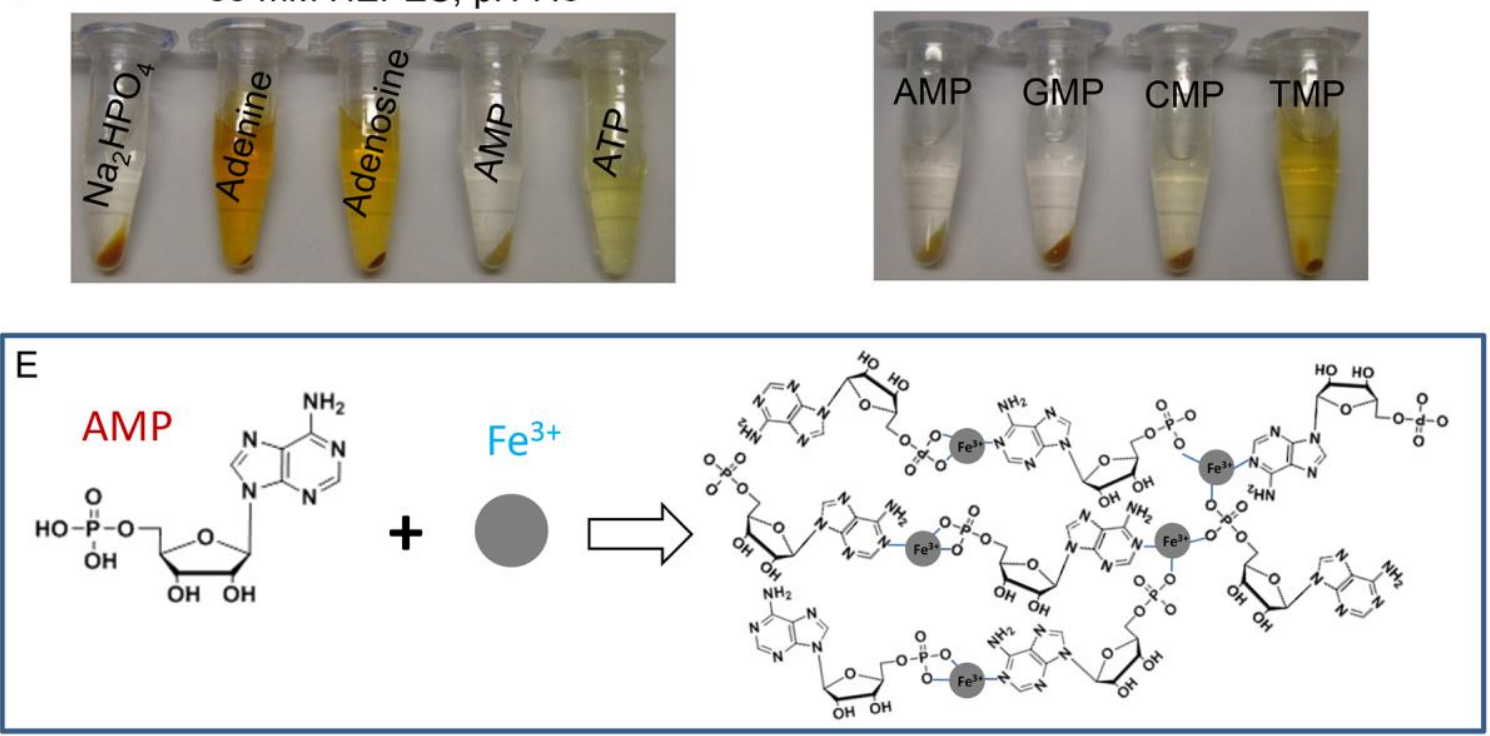

Figure 1. (A) A photograph of $\mathrm{Fe}^{3+}$ reacting with $\mathrm{AMP}$ in different concentrations of $\mathrm{pH} 7.4$

HEPES buffer. The actual $\mathrm{pH}$ values are also marked. (B) The CP precipitant weight and the AMP percentage remained in the supernatant after $\mathrm{Fe}^{3+}$ reacted with AMP and centrifugation for the samples in (A). A photograph of (C) $\mathrm{Fe}^{3+}$ reacting with phosphate, adenine, adenosine, AMP and ATP; and (D) $\mathrm{Fe}^{3+}$ reacting with AMP, GMP, CMP and TMP in 25 mM HEPES 
buffer ( $\mathrm{pH}$ 8.0). (E) A scheme of $\mathrm{Fe}^{3+}$ reacting with AMP forming CPs.

Magnetic $\mathrm{Fe}_{3} \mathrm{O}_{4} \mathrm{NP}$ seeded $\mathrm{CP}$ growth. While $\mathrm{Fe}^{3+}$ forms $\mathrm{CPs}$ with $\mathrm{AMP}$, this $\mathrm{CP}$ itself is not magnetic. To introduce magnetic property, we next tested whether it is possible to grow a CP layer around $\mathrm{Fe}_{3} \mathrm{O}_{4} \mathrm{NP}$ seeds (Figure 2A). AMP and $\mathrm{Fe}_{3} \mathrm{O}_{4} \mathrm{NPs}$ were first mixed to form an AMP coating and facilitate the seeded growth. After addition of $\mathrm{FeCl}_{3}$, brown precipitants immediately formed. The resulting materials were well dispersed (Figure 2B, the third tube). When exposed to an external magnetic field, the brown CPs were quickly attracted by the magnet and the supernatant became clear (Figure 2B, the last tube), indicating that the CPs were associated with the $\mathrm{Fe}_{3} \mathrm{O}_{4}$ NPs. The initial stage of interaction is likely to be physisorption and coordination interactions. Once a complete $\mathrm{CP}$ shell is formed, the $\mathrm{Fe}_{3} \mathrm{O}_{4}$ NPs became encapsulated by the shell.

To further confirm the seeded growth of $\mathrm{Fe}^{3+} / \mathrm{AMP} \mathrm{CPs}$, we characterized the products by TEM. Compared with the TEM image of naked $\mathrm{Fe}_{3} \mathrm{O}_{4}$ NPs (Figure 2C), a thin shell of $\mathrm{Fe}^{3+} / \mathrm{AMP} \mathrm{CP}$ was observed with a typical shell thickness of $\sim 10 \mathrm{~nm}$ (Figure 2D). For comparison, the TEM of the $\mathrm{Fe}^{3+} / \mathrm{AMP} \mathrm{CP}$ is also shown (Figure $2 \mathrm{~F}$ ), and it has a lighter electron density similar to the shell in Figure 2D, further confirming the shell composition. We named this core/shell materials $\mathrm{Fe}_{3} \mathrm{O}_{4} @ \mathrm{Fe}^{3+} / \mathrm{AMP}$.

In HEPES buffer ( $\mathrm{pH} 7.6$ ), the $\zeta$-potential of the $\mathrm{Fe}_{3} \mathrm{O}_{4} \mathrm{NPs}$ is $-24.0 \mathrm{mV}$, and that of $\mathrm{Fe}^{3+} / \mathrm{AMP}$ is $-33.3 \mathrm{mV}$, which is similar to the $\zeta$-potential of $\mathrm{Fe}_{3} \mathrm{O}_{4} @ \mathrm{Fe}^{3+} / \mathrm{AMP}(-32.0 \mathrm{mV})$. This also supports the coating of the iron oxide NPs with the $\mathrm{Fe}^{3+} / \mathrm{AMP}$ shell. 
A

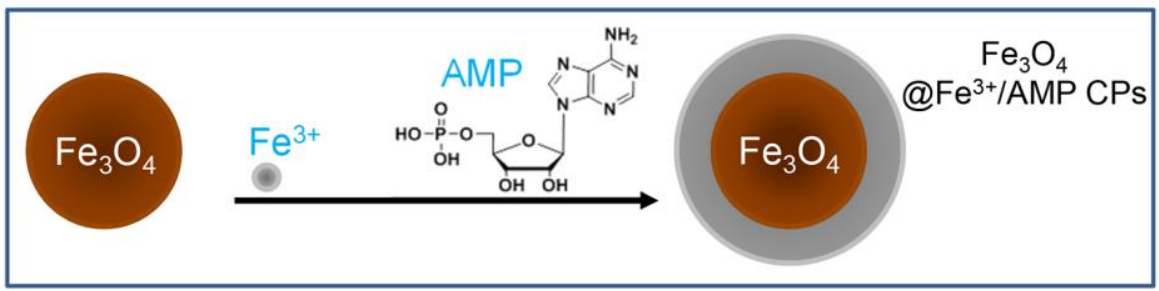

\section{B}
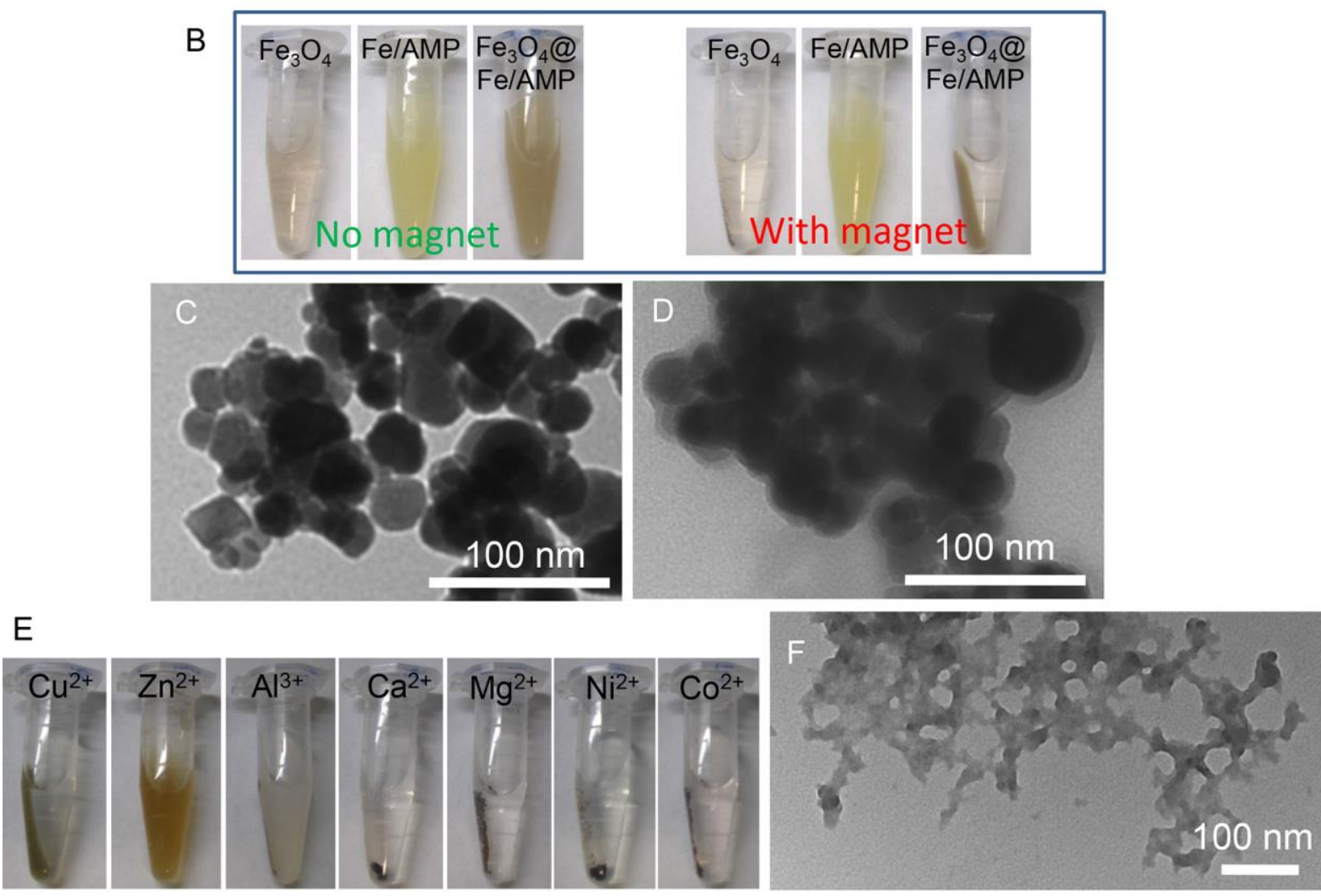

Figure 2. (A) A schematic illustration of seeded growth of $\mathrm{Fe}^{3+} / \mathrm{AMP} C \mathrm{CP}$ around $\mathrm{Fe}_{3} \mathrm{O}_{4} \mathrm{NPs}$.

(B) Photographs showing the samples of $\mathrm{Fe}_{3} \mathrm{O}_{4} \mathrm{NPs}, \mathrm{Fe}^{3+} / \mathrm{AMP} \mathrm{CPs}$, and $\mathrm{Fe}_{3} \mathrm{O}_{4} @ \mathrm{Fe}^{3+} / \mathrm{AMP}$ (left: without a magnet; right: after a magnet treatment). TEM images of (C) $\mathrm{Fe}_{3} \mathrm{O}_{4} \mathrm{NPs}$, (D) $\mathrm{Fe}_{3} \mathrm{O}_{4} @ \mathrm{Fe}^{3+} / \mathrm{AMP}$, and (F) $\mathrm{Fe}^{3+} / \mathrm{AMP}$ CPs. (E) Photographs showing the samples of other metal ions reacted with AMP in the presence of $\mathrm{Fe}_{3} \mathrm{O}_{4} \mathrm{NPs}$ after the magnet attraction.

Next we tested a few other divalent and trivalent metal ions for coating the $\mathrm{Fe}_{3} \mathrm{O}_{4} \mathrm{NPs}$. Among the tested metals, most could not form CPs or encapsulate $\mathrm{Fe}_{3} \mathrm{O}_{4}$ NPs (Figure 2E). For example, $\mathrm{Al}^{3+}$ formed CPs with $\mathrm{AMP}$, but it failed to entrap $\mathrm{Fe}_{3} \mathrm{O}_{4} \mathrm{NPs}$. $\mathrm{Cu}^{2+}$ did not form 
a stable complex, and a fraction of $\mathrm{Fe}_{3} \mathrm{O}_{4}$ NPs escaped from the networks after an exposure to the magnet (Figure S6). Although $\mathrm{Zn}^{2+} / \mathrm{AMP}$ also efficiently encapsulated $\mathrm{Fe}_{3} \mathrm{O}_{4}$ NPs, this material cannot be attracted by the magnet. It is likely that $\mathrm{Zn}^{2+} / \mathrm{AMP}$ is a nanogel (instead of nanoparticles) and it retains a lot of water; the magnetic field is insufficient to drag such a heavy hydrogel shell. Therefore, $\mathrm{Fe}^{3+}$ and AMP are an optimal combination that forms a stable shell.

Encapsulation of dyes. Encouraged by the successful seeded growth, we next tested the encapsulation property of $\mathrm{Fe}_{3} \mathrm{O}_{4} @ \mathrm{Fe}^{3+} / \mathrm{AMP}$ and its generality to entrap a broad range of materials all containing the magnetic core. A schematic illustrating the encapsulation of guest molecules is shown in Figure 3A.

We first studied the encapsulation of small molecules. Two common fluorescent dyes (fluorescein and rhodamine B) were employed to represent small molecule guests. Each guest molecule, AMP, and $\mathrm{Fe}_{3} \mathrm{O}_{4} \mathrm{NPs}$ were mixed with $\mathrm{FeCl}_{3}$. The samples were then exposed to the magnet, and the fluorescein almost completely disappeared in the supernatant, while rhodamine B was adsorbed by $\sim 50 \%$ (Figure 3B). In both cases, the CP shell has drastically improved the adsorption capacity compared to the naked $\mathrm{Fe}_{3} \mathrm{O}_{4} \mathrm{NPs}$. It is interesting to note that while fluorescein is negatively charged and the CP complex is also negatively charged, it still has higher adsorption compared to the charged neutral rhodamine B. Therefore, electrostatic interaction did not appear to play a major role here. Fluorescein might involve in coordination with positive $\mathrm{Fe}^{3+}$ ions using its carboxyl groups.

Encapsulation of protein and DNA. The binding capacity of $\mathrm{Fe}_{3} \mathrm{O}_{4} @ \mathrm{Fe}^{3+} / \mathrm{AMP}$ to proteins was next studied using fluorescein-labeled bovine serum albumin (BSA, pI=4.7). As shown 
in Figure 3C, $\mathrm{Fe}_{3} \mathrm{O}_{4} @ \mathrm{Fe}^{3+} / \mathrm{AMP}$ entrapped the BSA with over $90 \%$ efficiency, and it was easily separated by the magnet. For comparison, the $\mathrm{Fe}_{3} \mathrm{O}_{4}$ core adsorbed only $\sim 10 \%$ of the added BSA. The CP shell material alone should be able to encapsulate BSA, and we previously demonstrated protein encapsulation using $\mathrm{Zn}^{2+} / \mathrm{AMP} .{ }^{43} \mathrm{It}$ is likely that the $\mathrm{CP}$ grows around each protein to achieve encapsulation.
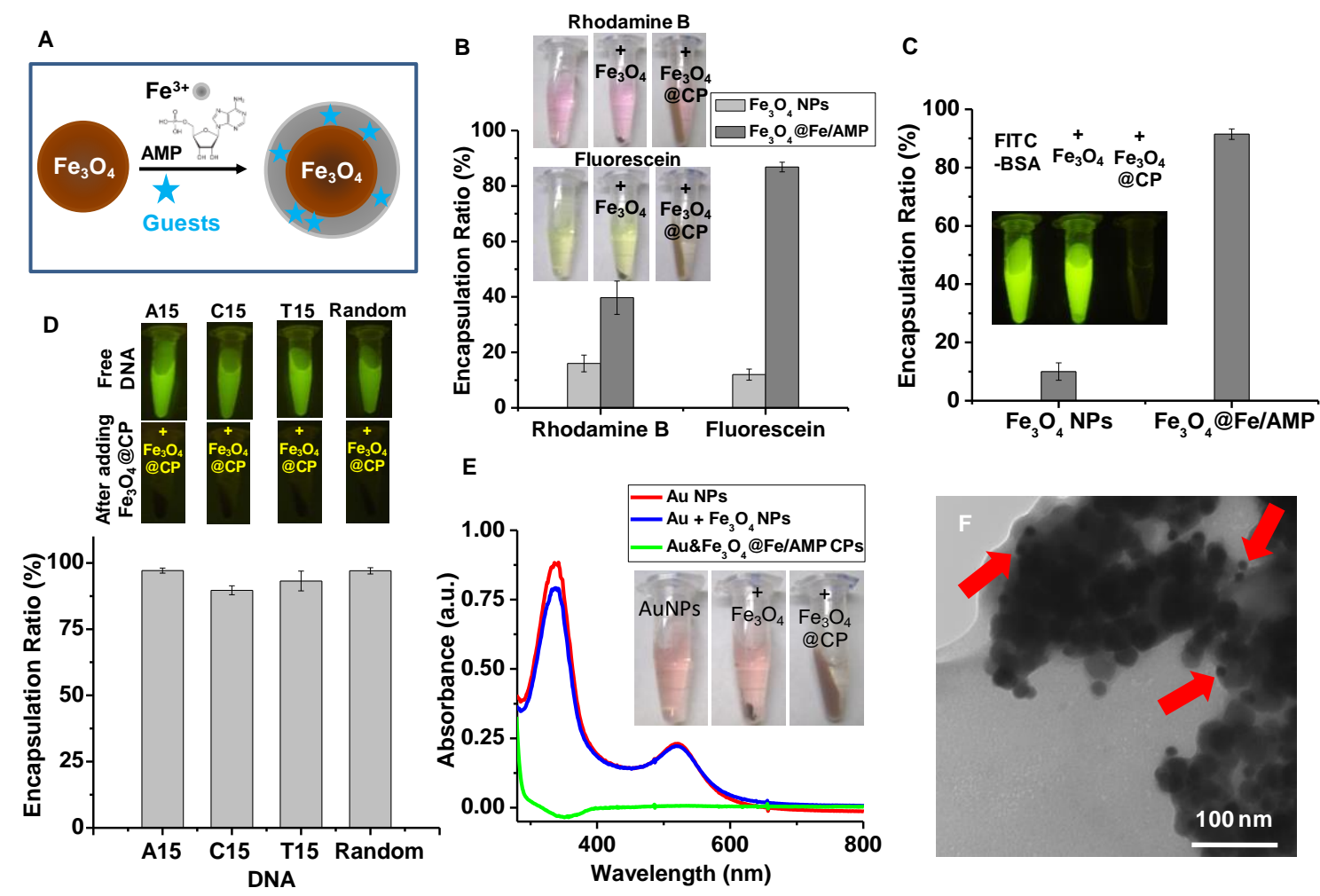

Figure 3. (A) A scheme showing guest encapsulation during the seeded growth of $\mathrm{Fe}^{3+} / \mathrm{AMP}$ $\mathrm{CP}$ around a magnetic $\mathrm{Fe}_{3} \mathrm{O}_{4}$ NP. Encapsulation ratio of (B) fluorescein and rhodamine B, (C) fluorescein-BSA, and (D) FAM-labeled DNA by $\mathrm{Fe}_{3} \mathrm{O}_{4} \mathrm{NPs}$ and by the NP with the $\mathrm{Fe}^{3+} / \mathrm{AMP} \mathrm{CP}$ shell. Insets: photographs of samples. (E) UV-vis spectra of the supernatant of AuNPs in HEPES buffer, after $\mathrm{Fe}_{3} \mathrm{O}_{4}$ adsorption and after $\mathrm{Fe}_{3} \mathrm{O}_{4} @ \mathrm{Fe}^{3+} / \mathrm{AMP}$ encapsulation (Inset: photographs of the samples). (F) TEM images of the AuNPs entrapped by $\mathrm{Fe}_{3} \mathrm{O}_{4} @ \mathrm{Fe}^{3+} / \mathrm{AMP}$ (red arrows pointed some encapsulated AuNPs). 
The encapsulation of DNA was next tested. To ensure generality, a few different sequences of FAM-labeled DNAs were used as the guest molecules (see Table S4 for the sequences). After encapsulation, the fluorescence was almost fully quenched likely due to the paramagnetic iron, similar to the FITC-BSA sample (Figure 3D). All the samples showed a high loading efficiency of over $90 \%$.

Encapsulation of NPs. The above successes in trapping various molecules prompted us to further investigate the encapsulation of inorganic NPs. For this purpose, gold NPs (AuNPs) were employed. Citrate-capped $13 \mathrm{~nm}$ AuNPs were mixed with AMP and $\mathrm{Fe}_{3} \mathrm{O}_{4}$ NPs. After adding $\mathrm{FeCl}_{3}$, brown precipitation formed. After using a magnet, all the red color from AuNPs was concentrated near the magnet, suggesting successful encapsulation (inset of Figure 3E). For comparison, the same amount of AuNPs was not adsorbed by the bare $\mathrm{Fe}_{3} \mathrm{O}_{4}$ NPs. The encapsulated AuNPs was quantified by measuring the supernatant UV-vis spectra in each sample (Figure 3E). To understand whether the encapsulated AuNPs remained dispersed, TEM was used (Figure 3F). The AuNPs were indeed dispersed and they appear to associate with the lighter electron density CPs covering the $\mathrm{Fe}_{3} \mathrm{O}_{4}$ NPs. Therefore, NPs can also be encapsulated in the CP layer. Note that the thickness of the CP layer was only around $10 \mathrm{~nm}$, and thus some of the $13 \mathrm{~nm}$ AuNPs were located on the edge of the layer. Smaller NPs might be better encapsulated in the interior of the layer.

Furthermore, we also tested the seeded growth of the CP layer on other nanoparticles, such as silica nanoparticles, carboxyl latex beads, amidine latex beads and AuNPs (Figure S7). It can be seen that $\mathrm{Fe}^{3+} / \mathrm{AMP}$ CPs could coat on all of these nanomaterials. Thus, this seeded growth method of coating CP layers on nanomaterials might be a general method 
beyond iron oxide.

The above studies indicate that this $\mathrm{CP}$ shell can incorporate many types of guests including small molecules, proteins, DNA, and AuNPs upon the magnetic core. All these were loaded at a much higher capacity compared to the simple adsorption by the naked NP core. This is attributed to the $3 \mathrm{D}$ nature of the shell and the guest molecules were entrapped not on the surface, but inside the whole shell.

Enhanced peroxidase nanozymes. After understanding the preparation of the CP-capped magnetic NPs and its ability to encapsulate guests, we next studied the functional aspect of this new material. Iron containing compounds such as $\mathrm{Fe}$ coordinated with tetra-amidomacrocyclic, ${ }^{44}$ and iron oxide NPs have peroxidase mimicking activity. ${ }^{45-48} \mathrm{We}$ suspect that the porous CP may also be an excellent peroxidase mimicking nanozyme. ${ }^{49} \mathrm{We}$ first compared the peroxidase activity of free $\mathrm{Fe}_{3} \mathrm{O}_{4}$, the $\mathrm{Fe}^{3+} / \mathrm{AMP} \mathrm{CP}$, and the $\mathrm{Fe}_{3} \mathrm{O}_{4} @ \mathrm{Fe}^{3+} / \mathrm{AMP}$ using 2,2' -azino-bis(3-ethylbenzothiazoline-6-sulphonic acid) (ABTS) as the chromogenic in the presence of $\mathrm{H}_{2} \mathrm{O}_{2}$ (Figure 4A). While free $\mathrm{Fe}_{3} \mathrm{O}_{4}$ had a moderate activity consistent with the literature report, ${ }^{46}$ its activity was quite low. The color change was modest after $10 \mathrm{~min}$, and it took more than $60 \mathrm{~min}$ to reach color saturation (Figure S8). The $\mathrm{Fe}^{3+} / \mathrm{AMP} \mathrm{CP}$ has a 3-fold higher activity compared to the free $\mathrm{Fe}_{3} \mathrm{O}_{4}$ at $10 \mathrm{~min}$, and the activity of $\mathrm{Fe}_{3} \mathrm{O}_{4} @ \mathrm{Fe}^{3+} / \mathrm{AMP}$ was the highest. We attribute this to the $\mathrm{Fe}_{3} \mathrm{O}_{4}$ core helping disperse the $\mathrm{CP}$ as a thin layer, thus increasing the surface area for reaction.

To understand the generality of this method, we also tested TMB as the substrate. In this case, no color change was observed with the free $\mathrm{Fe}_{3} \mathrm{O}_{4}$ NPs (Figure 4C), while a fast color change occurred with $\mathrm{Fe}^{3+} / \mathrm{AMP}$, and the catalytic activity maintained for $\mathrm{Fe}_{3} \mathrm{O}_{4} @ \mathrm{Fe}^{3+} / \mathrm{AMP}$. 
Different from the negatively charged ABTS, TMB is positively charged, and thus is repelled by the positively charged $\mathrm{Fe}_{3} \mathrm{O}_{4}$ at $\mathrm{pH} 4$ (the experimental condition). ${ }^{45}$ This explains the lack of color change for TMB. Coating the CP layer allowed the reaction of both cationic and anionic substrates and thus it has broadened the application range of this nanozyme.

Next, we tested the catalytic efficiency of $\mathrm{Fe}_{3} \mathrm{O}_{4} @ \mathrm{Fe}^{3+} /$ AMP CPs in buffers with different pH values (Figure 4D). The highest catalytic efficiency of $\mathrm{Fe}_{3} \mathrm{O}_{4} @ \mathrm{Fe}^{3+} / \mathrm{AMP}$ CPs was obtained at $\mathrm{pH} 4$, consistent with the literature report. ${ }^{45,50}$

A

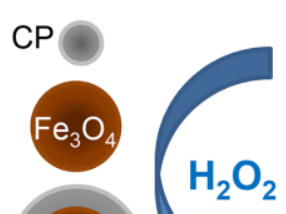

ABTS

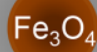

$\mathrm{H}_{2} \mathrm{O}_{2}$

$\mathrm{Fe}_{3} \mathrm{O}_{4}$
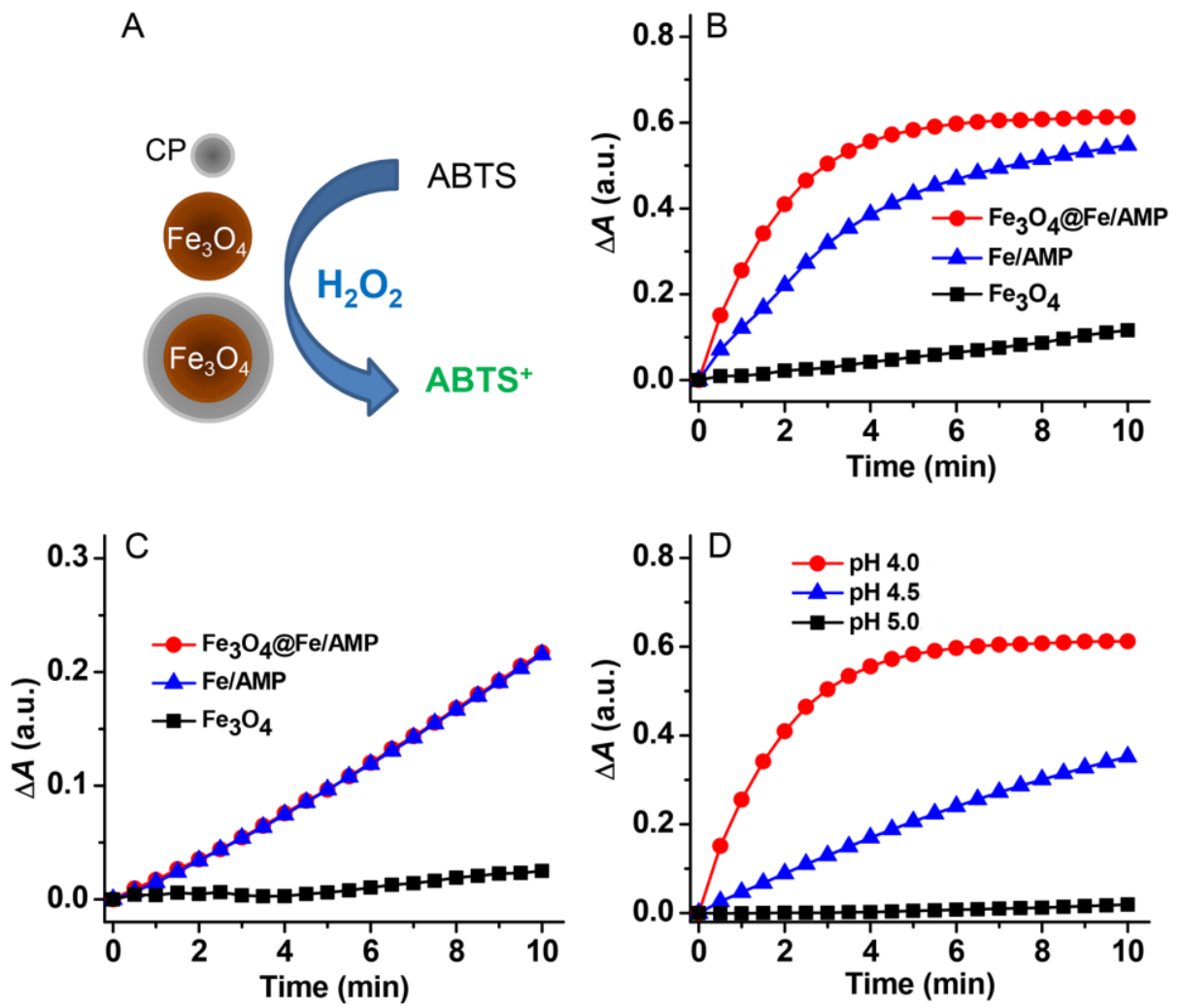

Figure 4. (A) A scheme of oxidation of ABTS in the presence of $\mathrm{H}_{2} \mathrm{O}_{2}$ by the peroxidase-like activity of the $\mathrm{Fe}^{3+} / \mathrm{AMP} \mathrm{CP}, \mathrm{Fe}_{3} \mathrm{O}_{4} \mathrm{NP}$, and the $\mathrm{Fe}_{3} \mathrm{O}_{4} @ \mathrm{Fe}^{3+} / \mathrm{AMP}$ NPs. Oxidization kinetics of (B) ABTS and (C) TMB by $\mathrm{H}_{2} \mathrm{O}_{2}$ in the presence of $\mathrm{Fe}_{3} \mathrm{O}_{4} @ \mathrm{Fe}^{3+} / \mathrm{AMP}$ CPs, $\mathrm{Fe}^{3+} / \mathrm{AMP}$ CPs, or $\mathrm{Fe}_{3} \mathrm{O}_{4}$. (D) Oxidization kinetics of ABTS by $\mathrm{H}_{2} \mathrm{O}_{2}$ with $\mathrm{Fe}_{3} \mathrm{O}_{4} @ \mathrm{Fe}^{3+} / A M P$ CPs at different $\mathrm{pH}$ values. 
An enzyme cascade for glucose detection. Now that we know this core/shell structure has a general and high peroxidase mimicking activity, and it can readily encapsulate proteins, we further explored its analytical applications. Glucose oxidase (GOx, $\mathrm{pI}=4.2)$ converts glucose to gluconic acid and produces $\mathrm{H}_{2} \mathrm{O}_{2}$ as a by-product, which is a co-substrate for the $\mathrm{Fe}_{3} \mathrm{O}_{4} @ \mathrm{Fe}^{3+} / \mathrm{AMP}$ nanozyme to oxidize ABTS. Therefore, encapsulating GOx into the CP layer may establish an enzyme cascade system such that the in-situ generated $\mathrm{H}_{2} \mathrm{O}_{2}$ can be efficiently used by the surrounding nanozyme (Figure 5A). ${ }^{43,51-55}$ At the same time, the CP shell may also protect GOx. To test this, we first evaluated the encapsulation efficiency of GOx by $\mathrm{Fe}_{3} \mathrm{O}_{4} @ \mathrm{Fe}^{3+} / \mathrm{AMP}$. Different concentrations of GOx (from 50 to $250 \mu \mathrm{g} / \mathrm{mL}$ ) were used. The formed products were separated by a magnet, and the amounts of incorporated GOx by $\mathrm{Fe}_{3} \mathrm{O}_{4} @ \mathrm{Fe}^{3+} / \mathrm{AMP}$ were calculated by the absorption intensities of the supernatant solutions using the Bradford assay (Figure S9). The encapsulation ratio was $\sim 90 \%$ in this whole GOx range we tested. Therefore, in addition to the previously tested BSA, this system can also encapsulate GOx.

The catalytic activity of the entrapped GOx in the $\mathrm{Fe}_{3} \mathrm{O}_{4} @ \mathrm{Fe}^{3+} / \mathrm{AMP}$ nanozyme was evaluated and compared with free GOx mixed with $\mathrm{Fe}_{3} \mathrm{O}_{4} @ \mathrm{Fe}^{3+} / \mathrm{AMP}$. The catalytic activity of $\mathrm{GOx}$ in the $\mathrm{Fe}_{3} \mathrm{O}_{4} @ \mathrm{Fe}^{3+} / \mathrm{AMP}$ complex was the highest (Figure 5B, red trace), consistent with the enzyme cascade reaction mechanism. In this system, $\mathrm{H}_{2} \mathrm{O}_{2}$ produced from the oxidation of glucose could rapidly reach the nearby peroxidase nanozyme and converts the ABTS substrate. In comparison, a simple mixing of these two resulted in a slightly slower kinetics (blue trace), while mixing GOx with $\mathrm{Fe}_{3} \mathrm{O}_{4} \mathrm{NP}$ had the lowest rate (green trace). 

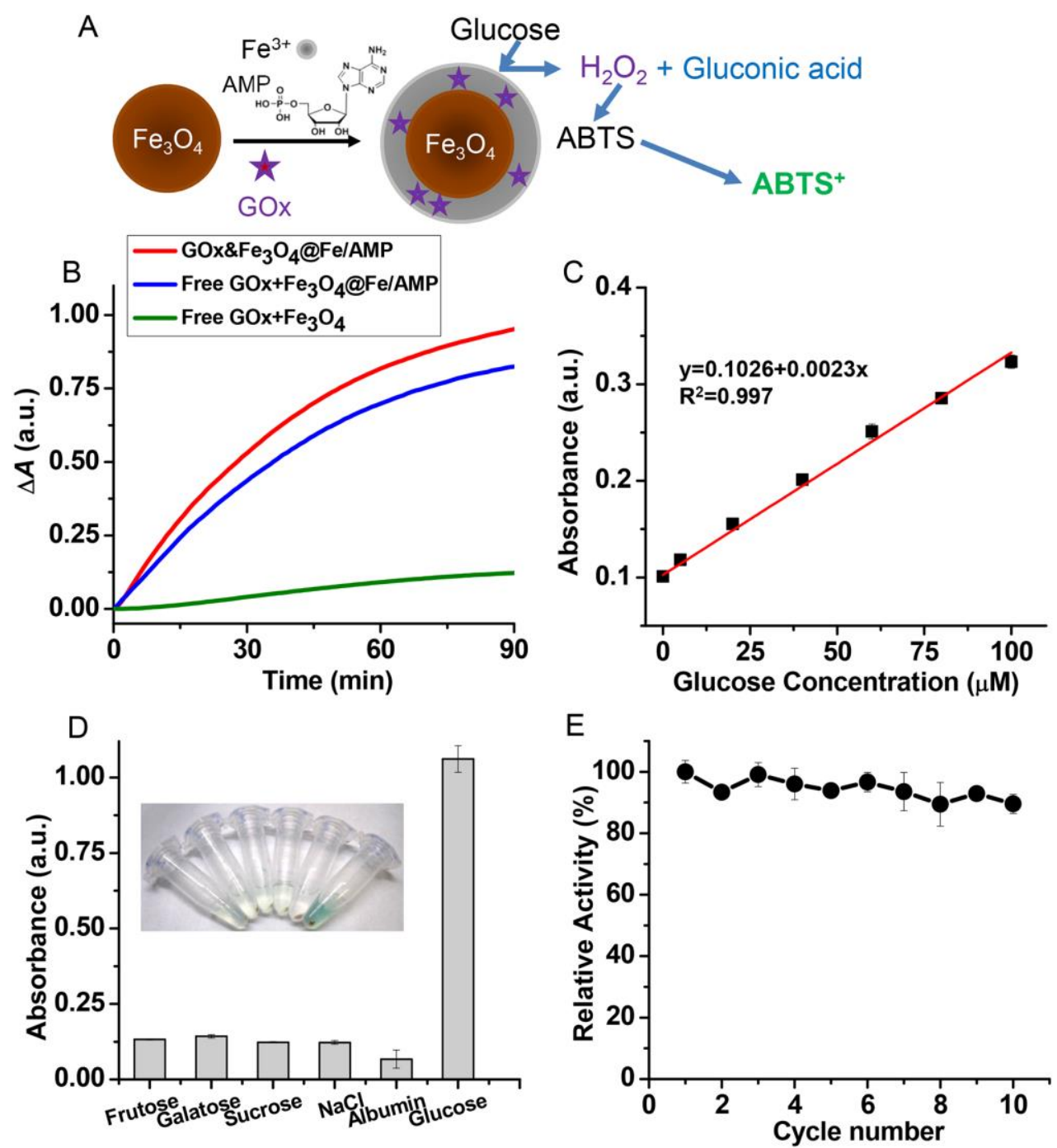

Figure 5. (A) A scheme of constructing an enzyme cascade system for glucose detection based on the color from ABTS oxidation. (B) Oxidization kinetics of ABTS by GOx\&Fe $\mathrm{O}_{4} @ \mathrm{Fe}^{3+} / \mathrm{AMP} \mathrm{CPs}$, free GOx with $\mathrm{Fe}_{3} \mathrm{O}_{4} @ \mathrm{Fe}^{3+} / \mathrm{AMP}$ CPs, free GOx with $\mathrm{Fe}^{3+} / \mathrm{AMP}$ CPs, or free GOx with $\mathrm{Fe}_{3} \mathrm{O}_{4}$ at the same amount. (C) Detection of glucose between 0 and $100 \mu \mathrm{M}$. (D) Determination of the selectivity of the GOx\&Fe $\mathrm{O}_{4} @ \mathrm{Fe}^{3+} / \mathrm{AMP}$ CPs (10 mM fructose, galactose, sucrose, glucose, or $\mathrm{NaCl}$, or $1 \mathrm{mg} / \mathrm{mL}$ of $\mathrm{BSA})$. (E) Relative activity of GOx\&Fe $\mathrm{O}_{4} @ \mathrm{Fe}^{3+} / \mathrm{AMP} C P s$ after reusing for 10 cycles.

Next, different concentrations of glucose were used to measure the sensitivity of the 
sensor. Figure 5C illustrates a good linearity between the absorbance and the concentration of glucose in the range of $0-100 \mu \mathrm{M}\left(R^{2}=0.993\right)$. The limit of detection (LOD) was calculated to be $1.4 \mu \mathrm{M}$ glucose based on the signal higher than three times of background variation. The selectivity for glucose was confirmed by monitoring the absorbance at $415 \mathrm{~nm}$ in the presence of various competing compounds (Figure 5D). With a magnetic core, this sensor can be readily regenerated after magnetic separation and washing. The relative activity of this sensor retained more than $90 \%$ after 10 washing cycles (Figure 5E). Finally, we tested the glucose content in extracted watermelon juice by this sensor, and the results were consistent with that by HPLC measurement (Table S6, Figure S10).

\section{Conclusions}

In summary, we succeeded in growing a $\mathrm{CP}$ shell made of $\mathrm{AMP}$ and $\mathrm{Fe}^{3+}$ on magnetic $\mathrm{Fe}_{3} \mathrm{O}_{4}$ NP seeds. A typical shell thickness is $\sim 10 \mathrm{~nm}$ and the shell can encapsulate a diverse range of guest molecules, including small molecule fluorophores, proteins, nucleic acids, and NPs. All these guests achieved a much higher loading capacity compared to that on the naked iron oxide NPs. The $\mathrm{Fe}^{3+} / \mathrm{AMP} \mathrm{CP}$ shell has significantly enhanced the peroxidase nanozyme activity of the $\mathrm{Fe}_{3} \mathrm{O}_{4}$ core. With entrapped GOx, an enzyme cascade reaction was realized allowing the detection of glucose down to $1.4 \mu \mathrm{M}$ with excellent selectivity and enzyme stability over repeated washing cycles. This work has provided an alternative method to functionalize magnetic NPs, and this new hybrid material will find applications in biosensor development, imaging, and drug delivery. This method of coating CP layers on nanomaterials might be a general method for many other materials. 


\section{Acknowledgement}

We thank Prof. Chunfang Li in Beijing Industrial Technician College for ICP. The financial support of this work is from the Beijing Higher Education Young Elite Teacher Project (YETP0520), the Fundamental Research Funds for the Central Universities (YS1407), the Beijing Natural Science Foundation (2162030), China Scholarship Council, and the Natural Sciences and Engineering Research Council of Canada (NSERC).

Supporting Information. The Supporting Information is available free of charge on the ACS Publications website at DOI: 10.1021/.

Effect of $\mathrm{NaCl}$ and $\mathrm{pH}$ on $\mathrm{CP}$ synthesis. TEM and DLS characterization of the CPs. ICP methods and results. Additional data on guest molecule entrapment. Table of DNA sequences.

\section{References:}

1. Lin, W.; Rieter, W. J.; Taylor, K. M. L., Modular Synthesis of Functional Nanoscale Coordination Polymers. Angew. Chem. Int. Ed. 2009, 48 (4), 650-658.

2. Wang, H.; Yang, R.; Yang, L.; Tan, W., Nucleic Acid Conjugated Nanomaterials for Enhanced Molecular Recognition. ACS Nano 2009, 3 (9), 2451-2460.

3. Rosi, N. L.; Mirkin, C. A., Nanostructures in Biodiagnostics. Chem. Rev. 2005, 105 (4), $1547-1562$.

4. Wang, C.; Xu, H.; Liang, C.; Liu, Y.; Li, Z.; Yang, G.; Cheng, L.; Li, Y.; Liu, Z., Iron 
Oxide @ Polypyrrole Nanoparticles as a Multifunctional Drug Carrier for Remotely Controlled Cancer Therapy with Synergistic Antitumor Effect. ACS Nano 2013, 7 (8), $6782-6795$.

5. Lin, L. S.; Cong, Z. X.; Cao, J. B.; Ke, K. M.; Peng, Q. L.; Gao, J.; Yang, H. H.; Liu, G.; Chen, X., Multifunctional $\mathrm{Fe}_{3} \mathrm{O}_{4} @$ Polydopamine Core-Shell Nanocomposites for Intracellular mRNA Detection and Imaging-Guided Photothermal Therapy. ACS Nano 2014, 8 (4), 3876-3883.

6. McCarthy, J. R.; Weissleder, R., Multifunctional Magnetic Nanoparticles for Targeted Imaging and Therapy. Adv. Drug Delivery Rev. 2008, 60 (11), 1241-1251.

7. Lu, A. H.; Salabas, E. L.; Schüth, F., Magnetic Nanoparticles: Synthesis, Protection, Functionalization, and Application. Angew. Chem. Int. Ed. 2007, 46 (8), 1222-1244.

8. Hao, R.; Xing, R.; Xu, Z.; Hou, Y.; Gao, S.; Sun, S., Synthesis, Functionalization, and Biomedical Applications of Multifunctional Magnetic Nanoparticles. Adv. Mater. 2010, 22 (25), 2729-2742.

9. Mulder, W. J. M.; Strijkers, G. J.; van Tilborg, G. A. F.; Griffioen, A. W.; Nicolay, K., Lipid-based Nanoparticles for Contrast-Enhanced MRI and Molecular Imaging. NMR Biomed. 2006, 19 (1), 142-164.

10. Cutler, J. I.; Zheng, D.; Xu, X.; Giljohann, D. A.; Mirkin, C. A., Polyvalent Oligonucleotide Iron Oxide Nanoparticle “Click” Conjugates. Nano Lett. 2010, 10 (4), $1477-1480$.

11. Li, J.; Hong, C. Y.; Wu, S. X.; Liang, H.; Wang, L. P.; Huang, G.; Chen, X.; Yang, H. H.; Shangguan, D.; Tan, W., Facile Phase Transfer and Surface Biofunctionalization of 
Hydrophobic Nanoparticles Using Janus DNA Tetrahedron Nanostructures. J. Am. Chem. Soc. 2015, 137 (35), 11210-11213.

12. Liu, Y.; Chen, T.; Wu, C.; Qiu, L.; Hu, R.; Li, J.; Cansiz, S.; Zhang, L.; Cui, C.; Zhu, G.; You, M.; Zhang, T.; Tan, W., Facile Surface Functionalization of Hydrophobic Magnetic Nanoparticles. J. Am. Chem. Soc. 2014, 136 (36), 12552-12555.

13. Hou, Y.; Zhou, J.; Gao, Z.; Sun, X.; Liu, C.; Shangguan, D.; Yang, W.; Gao, M., Protease-Activated Ratiometric Fluorescent Probe for $\mathrm{pH}$ Mapping of Malignant Tumors. ACS Nano 2015, 9 (3), 3199-3205.

14. Zeng, J.; Jing, L.; Hou, Y.; Jiao, M.; Qiao, R.; Jia, Q.; Liu, C.; Fang, F.; Lei, H.; Gao, M., Anchoring Group Effects of Surface Ligands on Magnetic Properties of $\mathrm{Fe}_{3} \mathrm{O}_{4}$ Nanoparticles: Towards High Performance MRI Contrast Agents. Adv. Mater. 2014, 26 (17), 2694-2698.

15. Liu, B.; Liu, J., DNA Adsorption by Magnetic Iron Oxide Nanoparticles and Its Application for Arsenate Detection. Chem. Commun. 2014, 50 (62), 8568-8570.

16. Deng, Y.; Qi, D.; Deng, C.; Zhang, X.; Zhao, D., Superparamagnetic High-Magnetization Microspheres with an $\mathrm{Fe}_{3} \mathrm{O}_{4} @ \mathrm{SiO}_{2}$ Core and Perpendicularly Aligned Mesoporous $\mathrm{SiO}_{2}$ Shell for Removal of Microcystins. J. Am. Chem. Soc. 2008, 130 (1), 28-29.

17. Song, Z. L.; Zhao, X. H.; Liu, W. N.; Ding, D.; Bian, X.; Liang, H.; Zhang, X. B.; Chen, Z.; Tan, W., Magnetic Graphitic Nanocapsules for Programmed DNA Fishing and Detection. Small 2013, 9 (6), 951-957.

18. Xu, Z.; Hou, Y.; Sun, S., Magnetic Core/Shell $\mathrm{Fe}_{3} \mathrm{O}_{4} / \mathrm{Au}$ and $\mathrm{Fe}_{3} \mathrm{O}_{4} / \mathrm{Au} / \mathrm{Ag}$ Nanoparticles with Tunable Plasmonic Properties. J. Am. Chem. Soc. 2007, 129 (28), 8698-8699. 
19. Josephson, L.; Tung, C. H.; Moore, A.; Weissleder, R., High-Efficiency Intracellular Magnetic Labeling with Novel Superparamagnetic-Tat Peptide Conjugates. Bioconjugate Chem. 1999, 10 (2), 186-191.

20. Chandra, V.; Park, J.; Chun, Y.; Lee, J. W.; Hwang, I. C.; Kim, K. S., Water-Dispersible Magnetite-Reduced Graphene Oxide Composites for Arsenic Removal. ACS Nano 2010, 4 (7), 3979-3986.

21. Kitagawa, S.; Kitaura, R.; Noro, S. I., Functional Porous Coordination Polymers. Angew. Chem. Int. Ed. 2004, 43 (18), 2334-2375.

22. Whittell, G. R.; Hager, M. D.; Schubert, U. S.; Manners, I., Functional Soft Materials from Metallopolymers and Metallosupramolecular Polymers. Nat. Mater. 2011, 10 (3), 176-188.

23. Liu, Y.; Tang, Z., Nanoscale Biocoordination Polymers: Novel Materials from an Old Topic. Chem.-Eur. J. 2012, 18 (4), 1030-1037.

24. Nishiyabu, R.; Hashimoto, N.; Cho, T.; Watanabe, K.; Yasunaga, T.; Endo, A.; Kaneko, K.; Niidome, T.; Murata, M.; Adachi, C.; Katayama, Y.; Hashizume, M.; Kimizuka, N., Nanoparticles of Adaptive Supramolecular Networks Self-Assembled from Nucleotides and Lanthanide Ions. J. Am. Chem. Soc. 2009, 131 (6), 2151-2158.

25. Zhou, H. C.; Long, J. R.; Yaghi, O. M., Introduction to Metal-Organic Frameworks. Chem. Rev. 2012, 112 (2), 673-674.

26. Imaz, I.; Rubio-Martínez, M.; Saletra, W. J.; Amabilino, D. B.; Maspoch, D., Amino Acid Based Metal-Organic Nanofibers. J. Am. Chem. Soc. 2009, 131 (51), 18222-18223.

27. Li, C.; Deng, K.; Tang, Z.; Jiang, L., Twisted Metal-Amino Acid Nanobelts: Chirality 
Transcription from Molecules to Frameworks. J. Am. Chem. Soc. 2010, 132 (23), 8202-8209.

28. Mantion, A.; Massüger, L.; Rabu, P.; Palivan, C.; McCusker, L. B.; Taubert, A., Metal-Peptide Frameworks (MPFs): “Bioinspired” Metal Organic Frameworks. J. Am. Chem. Soc. 2008, 130 (8), 2517-2526.

29. Pires, M. M.; Przybyla, D. E.; Chmielewski, J., A Metal-Collagen Peptide Framework for Three-Dimensional Cell Culture. Angew. Chem. Int. Ed. 2009, 121 (42), 7953-7957.

30. Ge, J.; Lei, J.; Zare, R. N., Protein-Inorganic Hybrid Nanoflowers. Nat. Nanotechnol. 2012, 7 (7), 428-432.

31. Sun, J.; Ge, J.; Liu, W.; Lan, M.; Zhang, H.; Wang, P.; Wang, Y.; Niu, Z., Multi-enzyme Co-embedded Organic-Inorganic Hybrid Nanoflowers: Synthesis and Application as a Colorimetric Sensor. Nanoscale 2014, 6 (1), 255-262.

32. Li, Z.; Zhang, Y.; Su, Y.; Ouyang, P.; Ge, J.; Liu, Z., Spatial Co-localization of Multi-enzymes by Inorganic Nanocrystal-protein Complexes. Chem. Commun. 2014, 50 (83), 12465-12468.

33. Navarro, J. A. R.; Lippert, B., Molecular Architecture with Metal Ions, Nucleobases and Other Heterocycles. Coord. Chem. Rev. 1999, 185-186, 653-667.

34. An, J.; Geib, S. J.; Rosi, N. L., Cation-Triggered Drug Release from a Porous Zinc-Adeninate Metal-Organic Framework. J. Am. Chem. Soc. 2009, 131 (24), 8376-8377.

35. Wang, F.; Liu, B.; Huang, P. J. J.; Liu, J., Rationally Designed Nucleobase and Nucleotide Coordinated Nanoparticles for Selective DNA Adsorption and Detection. 
Anal. Chem. 2013, 85 (24), 12144-12151.

36. Wei, H.; Li, B.; Du, Y.; Dong, S.; Wang, E., Nucleobase-Metal Hybrid Materials:

Preparation of Submicrometer-Scale, Spherical Colloidal Particles of Adenine-Gold(III) via a Supramolecular Hierarchical Self-Assembly Approach. Chem. Mater. 2007, 19 (12), 2987-2993.

37. Purohit, C. S.; Verma, S., A Luminescent Silver-Adenine Metallamacrocyclic Quartet. J. Am. Chem. Soc. 2006, 128 (2), 400-401.

38. Sukul, P. K.; Malik, S., Supramolecular Hydrogels of Adenine: Morphological, Structural and Rheological Investigations. Soft Matter 2011, 7 (9), 4234-4241.

39. Liang, H.; Zhang, Z.; Yuan, Q.; Liu, J., Self-healing Metal-coordinated Hydrogels Using Nucleotide Ligands. Chem. Commun. 2015, 51 (82), 15196-15199.

40. Verma, S.; Mishra, A. K.; Kumar, J., The Many Facets of Adenine: Coordination, Crystal Patterns, and Catalysis. Acc. Chem. Res. 2010, 43 (1), 79-91.

41. Lopez, A.; Liu, J., Light-Activated Metal-Coordinated Supramolecular Complexes with Charge-Directed Self-Assembly. J. Phys. Chem. C 2013, 117 (7), 3653-3661.

42. Lopez, A.; Liu, J., DNA-templated Fluorescent Gold Nanoclusters Reduced by Good's Buffer: from Blue-emitting Seeds to Red and Near Infrared Emitters. Can. J. Chem. 2015, 93 (6), 615-620.

43. Liang, H.; Jiang, S.; Yuan, Q.; Li, G.; Wang, F.; Zhang, Z.; Liu, J., Co-immobilization of Multiple Enzymes by Metal Coordinated Nucleotide Hydrogel Nanofibers: Improved Stability and an Enzyme Cascade for Glucose Detection. Nanoscale 2016, 8 (11), 6071-6078. 
44. Kumari, S.; Dhar, B. B.; Panda, C.; Meena, A.; Sen Gupta, S., Fe-TAML Encapsulated Inside Mesoporous Silica Nanoparticles as Peroxidase Mimic: Femtomolar Protein Detection. ACS Appl. Mater. Interfaces 2014, 6 (16), 13866-13873.

45. Liu, B.; Liu, J., Accelerating Peroxidase Mimicking Nanozymes Using DNA. Nanoscale 2015, 7 (33), 13831-13835.

46. Gao, L.; Zhuang, J.; Nie, L.; Zhang, J.; Zhang, Y.; Gu, N.; Wang, T.; Feng, J.; Yang, D.; Perrett, S.; Yan, X., Intrinsic Peroxidase-like Activity of Ferromagnetic Nanoparticles. Nat. Nanotechnol. 2007, 2 (9), 577-583.

47. Wang, X.; Hu, Y.; Wei, H., Nanozymes in Bionanotechnology: from Sensing to Therapeutics and Beyond. Inorg. Chem. Front. 2016, 3 (1), 41-60.

48. Wei, H.; Wang, E., $\mathrm{Fe}_{3} \mathrm{O}_{4}$ Magnetic Nanoparticles as Peroxidase Mimetics and Their Applications in $\mathrm{H}_{2} \mathrm{O}_{2}$ and Glucose Detection. Anal. Chem. 2008, 80 (6), 2250-2254.

49. Wei, H.; Wang, E., Nanomaterials with Enzyme-like Characteristics (Nanozymes): Next-Generation Artificial Enzymes. Chem. Soc. Rev. 2013, 42 (14), 6060-6093. 50. Lu, C.; Liu, X.; Li, Y.; Yu, F.; Tang, L.; Hu, Y.; Ying, Y., Multifunctional Janus Hematite-Silica Nanoparticles: Mimicking Peroxidase-Like Activity and Sensitive Colorimetric Detection of Glucose. ACS Appl. Mater. Interfaces 2015, 7 (28), $15395-15402$.

51. Grotzky, A.; Nauser, T.; Erdogan, H.; Schlüter, A. D.; Walde, P., A Fluorescently Labeled Dendronized Polymer-Enzyme Conjugate Carrying Multiple Copies of Two Different Types of Active Enzymes. J. Am. Chem. Soc. 2012, 134 (28), 11392-11395.

52. Wang, F.; Liu, X.; Lu, C.-H.; Willner, I., Cysteine-Mediated Aggregation of Au 
Nanoparticles: The Development of a $\mathrm{H}_{2} \mathrm{O}_{2}$ Sensor and Oxidase-Based Biosensors. ACS Nano 2013, 7 (8), 7278-7286.

53. Peters, R. J. R. W.; Marguet, M.; Marais, S.; Fraaije, M. W.; van Hest, J. C. M.;

Lecommandoux, S., Cascade Reactions in Multicompartmentalized Polymersomes.

Angew. Chem. Int. Ed. 2014, 53 (1), 146-150.

54. Yoshii, T.; Onogi, S.; Shigemitsu, H.; Hamachi, I., Chemically Reactive Supramolecular Hydrogel Coupled with a Signal Amplification System for Enhanced Analyte Sensitivity. J. Am. Chem. Soc. 2015, 137 (9), 3360-3365.

55. Cheng, H.; Zhang, L.; He, J.; Guo, W.; Zhou, Z.; Zhang, X.; Nie, S.; Wei, H., Integrated Nanozymes with Nanoscale Proximity for in vivo Neurochemical Monitoring in Living Brains. Anal. Chem. 2016, 88 (10), 5489-5497. 